\title{
SINTESIS BAHAN HIBRIDA AMINO-SILIKA DARI ABU SEKAM PADI MELALUI PROSES SOL-GEL
}

\author{
Sriyanti, Taslimah ${ }^{1)}$, Nuryono dan Narsito ${ }^{2)}$ \\ 1) Jurusan Kimia FMIPA Universitas Diponegoro, Semarang \\ 2) Jurusan Kimia FMIPA Universitas Gadjah Mada, Yogyakarta
}

\begin{abstract}
ABSTRAK
Silika dengan imobilisasi gugus amino dengan bahan dasar abu sekam padi telah dibuat melalui proses sol-gel. Sebagai perbandingan, dibuat pula silika gel tanpa gugus organik.Larutan mendidih natrium silikat $(1,5 \mathrm{~N})$ ditambahkan pada abu sekam padi, kemudian filtratnya dipisahkan sebagai larutan natrium silikat. Selanjutnya, kedua filtrat digunakan untuk sintesis silika gel dengan dan tanpa gugus organik. 3-Aminopropiltrimetoksisilan (APTS) ditambahkan ke dalam larutan natrium silikat, dilanjutkan dengan penambahan asam klorida perlahan-lahan sampai $\mathrm{pH} 7$ dan $\mathrm{pH}$ 3. Gel yang terbentuk diperam selama 18 jam dengan temperatur $80^{\circ} \mathrm{C}$, dicuci dengan air kemudian dikeringkan pada temperatur $80^{\circ} \mathrm{C}$ selama 9 jam. Silika gel dibuat dengan cara yang sama. Kedua produk dikarakterisasi dengan FTIR dan XRD, serta diuji kemampuan adsorpsinya terhadap logam Ni (II). Hasil menunjukkan bahwa silika gel hasil mempunyai pola yang sama dengan silika Kiesel Gel 60 dari Merck, baik spektra FTIR maupun defraktogram XRDnya, sedangkan bahan hibrida amino-silika mempunyai puncak-puncak serapan yang menunjukkan adanya gugus amin $\left(-\mathrm{NH}_{2}\right)$ dan rantai alifatik $\left(-\mathrm{CH}_{2}-\right)$ di samping kesamaan pola dengan silika standar. Dalam uji adsorpsi, amino-silika mengadsorpsi Ni (II) lebih tinggi dibanding silika gel dengan kapasitas adsorpsi masing-masing 0, $106 \mathrm{~mol} / \mathrm{g}$ adsorben dan 0,0088 mol/g adsorben.
\end{abstract}

Kata Kunci: abu sekam padi, hibrida amino-silikai, silika gel, 3-aminopropil-trimetoksisilan.

\section{SYNTHESIS OF AMINO-SILICA HYBRID FROM RICE HULL ASH BY SOL- GEL METHODE}

\begin{abstract}
Silicas with immobilised amino group from rice hull ash have been prepared through solgel methode. For comparison purposes, silica gel without amino group was also prepared. Sodium hydroxide boiled solution $(1.5 \mathrm{~N})$ were added to rice hull ash, then the filtrat were separated as sodium silicate solution. Moreover, both the filtrat were used to synthesis the silica gel either with molecul organic or not. 3-aminopro-piltrimethoxysilane were added to sodium silicate solution, and then hydrochloride acid were added slowly until $\mathrm{pH} 7$ and 3. The gel were aging at $80^{\circ} \mathrm{C}$ for 18 hours, wash with water and dried at $80^{\circ} \mathrm{C}$ for 9 hours. Silica gel without amino group immobilization were done by the same way. Both the product were characterize with FTIR, XRD and $\mathrm{Ni}$ (II) adsorption.The results shows that the silica gel were obtained had similar pattern in FTIR and XRD with silicas Kiesel Gel 60 from Merck, while the hybrid of amino-silica had new peaks in organic vibration that indicated ammine group $\left(-\mathrm{NH}_{2}\right)$ and chain aliphatic $\left(-\mathrm{CH}_{2}-\right)$ area besides the similar pattern with silicas standard. The adsorption of $\mathrm{Ni}$ (II) on amino-silica had higher capacity adsorption (0.106 mol/g adsorbent) than silica gel (0.0088 mol/g adsorbent).
\end{abstract}

Key words: rice hull ash, silica gel, amino silica hybrid, 3-aminopripiltrimethoxysilane.

\section{PENDAHULUAN}

Silika secara luas banyak digunakan dalam penyulingan minyak tumbuhan, produk farmasi, detergen, adesif, kolom kromatografi dan keramik. Natrium silikat sebagai prekursor untuk produksi silika secara langsung kebanyakan dibuat dari peleburan pasir kuarsa dengan natrium karbonat pada temperatur $1300^{\circ} \mathrm{C}$ (Brinker dan Scherer, 1990).

Kelemahan penggunaan pasir kuarsa sebagai bahan dasar pembuatan bahan berbasis silika adalah tingginya kekristalan bahan dan 
banyaknya komponen logam. Tingginya kekristalan mengakibatkan proses peleburan berlangsung pada temperatur tinggi dan perlu waktu yang relatif lama. Banyaknya komponen logam berakibat pada rendahnya kemurnian logam yang dihasilkan. Berdasarkan komposisi kimia dengan silika merupakan komponen utama (94,5 \%, Priyosulistyo, 1999), abu sekam padi kemungkinan dapat menggantikan posisi pasir kuarsa sebagai bahan pembuatan silika gel. Pembuatan silika gel dari abu sekam padi diperkirakan lebih menguntungkan daripada dengan menggunakan pasir kuarsa. Di samping kandungan silika yang tinggi, abu sekam padi bersifat amorf dan tidak sekeras pasir kuarsa sehingga untuk peleburan abu sekam padi tidak memerlukan waktu yang lama dan temperatur yang tinggi.

Penambahan suatu bahan aktif pada matriks atau bahan pendukung (kebanyakan padatan) untuk meningkatkan fungsi dari bahan aktif tersebut dikenal dengan proses imobilisasi. Dewasa ini penggunaan padatan anorganik sebagai matriks imobilisasi suatu bahan tertentu telah banyak dilakukan seperti untuk pembuatan adsorben selektif, katalis imobilisasi enzim dan lain-lain.

Proses penambahan bahan aktif terhadap matriks pendukung ini dapat dilakukan melalui berbagai cara. Adsorpsi fisik merupakan cara yang paling mudah dilakukan. Sebagai contoh adalah imobilisasi senyawa organik 2merkaptobenzotiazol pada padatan pendukung zeolit alam untuk mengadsorpsi Cd (II) dan $\mathrm{Fe}$ (III) (Sriyanti dkk., 2001). Selain mudah dilakukan, dalam metode ini harus digunakan suatu bahan perantara, seperti polistirena, tetapi interaksi antara padatan dan bahan yang diimobilkan tidak cukup kuat karena interaksinya bersifat fisik, sehingga mudah untuk terlepas kembali.

Metode lain yang banyak digunakan adalah melalui pengikatan kovalen. Metode ini menghasilkan suatu bahan terimobilisasi yang interaksinya kuat, tetapi prosesnya relatif rumit dan memerlukan waktu yang relatif lama.

Metode lain yang banyak dikembangkan saat ini adalah melalui proses sol-gel, yaitu penambahan bahan yang diimobilkan dilakukan pada saat matriks berbentuk sol, kemudian menuju ke arah pembentukan padatan (gel) bersamaan dengan terbentuknya padatan pendukung. Metode ini relatif mudah dilakukan, tidak memerlukan waktu yang lama dan interaksi antara padatan dan bahan yang diimobilkan relatif kuat.

Padatan yang banyak digunakan sebagai matriks pendukung kebanyakan adalah zeolit, clay, alumina dan silika (Oscik, 1982). Zeolit merupakan material anorganik yang mempunyai kestabilan termal yang cukup tinggi, tetapi poripori kaku yang dimiliki menyebabkan zeolit tidak mudah untuk dimodifikasi. Demikian juga dengan clay, pori antar layernya mudah untuk dimodifikasi tetapi sifat mudah mengembang dari clay (swelling), untuk tujuan-tujuan tertentu kadang tidak dikehendaki. Alumina juga mempunyai stabilitas termal yang tinggi, tetapi sifatnya yang cenderung polar juga harus dipertimbangkan.

Silika mempunyai kelebihan tersendiri dibanding bahan yang lain, karena secara kimia bersifat inert, hidrofobik dan transparan. Selain itu juga menunjukkan kekuatan mekanik dan stabilitas termal yang tinggi dan tidak mengembang dalam pelarut organik (Bhatia, 2000).

Proses sol-gel adalah pelarutan pada temperatur rendah yang merupakan dasar pada sintesis gelas. Pembentukan matriks silika dicapai dengan hidrolisis pada suatu alkoksi (biasanya tetrametil orto silikat/ TMOS) diikuti kondensasi untuk menghasilkan suatu polimer jaringan $\mathrm{SiO}_{2}$ dengan jembatan okso. Hidrolisis menghasilkan konversi ikatan Si-OR ke Si-OH yang memadat membentuk suatu polimer berjembatan okso Si-O-Si. Reaksi ini terjadi dalam suatu daerah terlokalisasi menuju pembentukan partikel sol. Derajat pertautan 
silang sebagai hasil polikondensasi meningkat dan viskositas sol juga meningkat. Kekentalan material kemudian mengeras menuju pembentukan suatu gel yang porous (Brinker dan Scherer, 1990).

Proses sol gel dimulai dengan mengasamkan larutan natrium silikat sampai terbentuk gel karena silika mempunyai kelarutan yang tinggi pada pH > 10 (Scott, 1993). Sriyanti dkk. (2004) melaporkan bahwa pengasaman natrium silikat dengan $\mathrm{HCl}$ menyebabkan pembentukan gel yang sangat cepat ( $\mathrm{pH}$ : 9-7), dan jika $\mathrm{HCl}$ terusmenerus ditambahkan maka gel akan melarut kembali. Hal ini kemungkinan disebabkan ion logam $\mathrm{Na}$ akan terjebak ke dalam matriks gel dan tidak larut dengan pencucian. Hal ini sejalan dengan pendapat Kalapathy dkk. (2000), bahwa penggunaan $\mathrm{HCl}$ pada pengasaman langsung menghasilkan silika gel dengan kandungan $\mathrm{Na}$ yang tinggi (> 4\%). Pengendalian proses pembentukan gel (gelasi) kemungkinan dapat dilakukan dengan mengamati pembentukan gel pada kondisi tertentu (melalui variasi jenis asam, jenis prekursor dan pengaturan keasaman medium).

Pada penelitian ini dikaji pengaruh masuknya gugus organik dan pengaturan keasaman medium (pH gelasi) terhadap karakter gel yang dihasilkan. Karakterisasi hasil dilakukan dengan FTIR spektroskopi dan XRD, serta uji adsorpsi terhadap ion logam $\mathrm{Ni}$ (II).

\section{METODE PENELITIAN}

\section{Bahan dan Peralatan}

Bahan yang digunakan dalam penelitian ini meliputi: sekam padi dari daerah Sragen, Jawa Tengah, $\mathrm{NaOH}$ pelet, $\mathrm{HCl}$, dan $\mathrm{NiCl}_{2} \cdot 6 \mathrm{H}_{2} \mathrm{O}$ dari Merck dan 3-aminopropiltrimetoksisilan dari Sigma. Peralatan utama yang digunakan adalah tungku pemanas (furnace), oven, hot plate, lumpang porselen dan ayakan 200 mesh, spektrofotometer Shimadzhu FTIR-8201 PC (lab. Kimia Organik FMIPA UGM), Defraktometer sinar-x Shimadzhu X-2000 dan
Spektrofotometer serapan atom model Hitachi Z-8000 (Lab. Kimia Analitik FMIPA UGM).

\section{Preparasi abu sekam padi}

Sekam padi dari daerah Sragen, Jawa Tengah, dikeringkan di bawah matahari dan dibersihkan dari kotoran-kotoran pengikut seperti daun-daun padi, pasir dan kerikil. Selanjutnya dipanaskan di atas kompor hingga membentuk arang yang berwarna hitam. Arang dimasukkan ke dalam cawan porselen untuk selanjutnya dipanaskan dalam tungku pemanas (furnace) selama 4 jam dengan temperatur $700^{\circ} \mathrm{C}$. Abu yang dihasilkan digerus kemudian diayak hingga lolos ayakan 200 mesh.

\section{Pembuatan larutan natrium silikat}

Dibuat larutan $\mathrm{NaOH} 1,5 \mathrm{~N}$ dari $\mathrm{NaOH}$ pelet yang ada. Enampuluh mililiter larutan $\mathrm{NaOH}$ 1,5 $\mathrm{N}$ ditambahkan ke dalam abu sekam, kemudian dididihkan sambil diaduk. Setelah dingin disaring, dan residu ditambah lagi dengan $60 \mathrm{~mL}$ larutan $\mathrm{NaOH}$ 1,5 $\mathrm{N}$ dan kembali dididihkan setelah dingin, disaring dan filtratnya disatukan denagn fitrat pertama sebagai larutan natrium silikat dan disimpan dalam botol plastik.

\section{Pembuatan silika gel dan hibrida amino- silika}

Sebagai pembanding, sebelum dibuat bahan hibrida melalui proses sol-gel, terlebih dahulu dibuat silika gel dari natrium silikat yang sudah disiapkan. Larutan natrium silikat yang berasal dari $10 \mathrm{~g}$ abu sekam ditambah dengan $\mathrm{HCl} 6 \mathrm{~N}$ bertetes-tetes, sambil diaduk hingga terbentuk gel berwarna putih pada $\mathrm{pH} 7$ dan 3. Gel yang terbentuk ditambah aquades, kemudian dipanaskan $80^{\circ} \mathrm{C}$ selama 18 jam. Setelah dingin dicuci dengan air dan dikeringkan $80^{\circ} \mathrm{C}$ selama 9 jam, selanjutnya digerus dan diayak hingga lolos ayakan 200 mesh. Pembuatan silika gel termodifikasi gugus organik dilakukan seperti pada pembuatan silika gel, tetapi sebelum penambahan asam ditambahkan terlebih dahulu 3-aminopropiltrimetoksisilan (APTS) dengan perbandingan (natrium silikat dari $10 \mathrm{~g}$ abu: 2 $\mathrm{mL}$ (APTS). Produk yang dihasilkan selanjutnya 
dikarakterisasi dengan spektrofotometer Inframerah dan defraktometer sinar-x.

\section{Adsorpsi Ni (II)}

Sebanyak $10 \mathrm{~mL}$ larutan ion logam Ni (II) dengan variasi konsentrasi : 5, 10, 20, 50, 100, dan $200 \mathrm{mg} / \mathrm{L}$, masing-masing diinteraksikan dengan $100 \mathrm{mg}$ adsorben silika gel dan aminosilika selama 30 menit kemudian disaring. Konsentrasi ion logam yang tersisa dalam larutan ditentukan dengan AAS, dan jumlah ion logam yang teradsorpsi dihitung dari selisih jumlah logam sebelum dan sesudah adsorpsi.

\section{HASIL DAN PEMBAHASAN}

\section{Natrium silikat hasil ekstraksi abu sekam padi}

Pembuatan larutan natrium silikat sebagai prekursor pembuatan silika gel maupun bahan hibrida amino-silika, diawali dengan pengabuan sekam padi. Sekam padi diambil dari daerah Sragen, Jawa Tengah, yang merupakan salah satu daerah penghasil padi yang cukup potensial, sehingga sekam merupakan limbah yang sangat berlimpah dan belum dimanfaatkan secara optimal.

Sekam padi dikeringkan di bawah terik matahari, dan dibersihkan dari pengotorpengotor fisik, seperti daun-daun dan batang padi maupun kerikil-kerikil. Selanjutnya sekam yang sudah kering diarangkan di atas kompor minyak sampai berwarna hitam. Arang yang berwarna hitam ini kemudian dipanaskan dalam tungku pemanas (furnace) pada suhu $700^{\circ} \mathrm{C}$ selama 4 jam. Pemanasan ini bertujuan untuk menghilangkan fraksi organik dari sekam padi, sehingga yang tertinggal hanya fraksi anorganiknya saja. Abu yang dihasilkan berwarna putih keabu-abuan, dan untuk menyeragamkan ukuran, abu tersebut digerus dan diayak dengan ayakan 200 mesh, selanjutnya siap digunakan sebagai bahan dasar.

Tahap selanjutnya adalah mengekstrak silika yang ada dalam abu sekam padi. Sriyanti dkk. (2004), telah melakukan ekstraksi silika dari abu sekam padi melalui dua cara, yaitu ekstraksi basah dan ekstraksi kering. Ekstraksi kering merupakan ekstraksi yan umum dilakukan, yaitu dengan melebur abu sekam dengan $\mathrm{NaOH}$ pada pemanasan $500^{\circ} \mathrm{C}$ selama 30 menit; sedangkan cara basah adalah dengan mengekstrak abu sekam padi menggunakan larutan $\mathrm{NaOH}$ mendidih, seperti yang dilakukan oleh Kalapathy dkk. (2000). Menurut Sriyanti dkk (2004), silika gel yang dihasilkan dari prekursor larutan natrium silikat hasil dari ekstraksi kering maupun basah secara kualitatif tidak memiliki perbedaan yang signifikan. Hal tersebut bisa dilihat dari spektra inframerah dari keduanya. Menurut Nuryono dkk. (2004), ekstraksi silika dari abu sekam padi secara basah optimum pada konsentrasi $\mathrm{NaOH}$ sebesar 1,5 N. Untuk itu dalam penelitian ini dilakukan ekstraksi basah terhadap abu sekam padi dari Sragen dengan $\mathrm{NaOH} 1,5 \mathrm{~N}$.

Reaksi pengabuan yang terjadi menurut Nuryono, dkk., 2004 adalah sebagai berikut:

Senyawa $\mathrm{C}, \mathrm{H}$, dan $\mathrm{Si}+\mathrm{O}_{2} \rightarrow \mathrm{CO}_{2}(\mathrm{~g})+\mathrm{H}_{2} \mathrm{O}$ $(\mathrm{g})+\mathrm{SiO}_{2}(\mathrm{p})$

Dimungkinkan juga terjadi kondensasi gugus silanol $(\equiv \mathrm{Si}-\mathrm{OH})$ seperti penjelasan Iler (1979):

$2 \equiv \mathrm{Si}-\mathrm{OH} \rightarrow \equiv \mathrm{Si}-\mathrm{O}-\mathrm{Si} \equiv+\mathrm{H}_{2} \mathrm{O}$

Pada ekstraksi silika dari abu sekam hingga terbentuk larutan natrium silikat mengikuti reaksi sebagai berikut (Scott, 1993):

$\mathrm{SiO}_{2}+2 \mathrm{NaOH} \rightarrow \mathrm{Na}_{2} \mathrm{SiO}_{3}+\mathrm{H}_{2} \mathrm{O}$

Dari 90 gram abu, setelah diekstraksi dengan $540 \mathrm{~mL} \mathrm{NaOH}$ 1,5 $\mathrm{N}$ dan penambahan aquades, diperoleh larutan natrium silikat sebanyak 620 $\mathrm{mL}$, yang selanjutnya digunakan sebagai prekursor pada pembuatan adsorben.

\section{Hibrida Amino-Silika dan silika gel}

Pembuatan hibrida amino-silika diawali dengan menambahkan $2 \mathrm{~mL}$ ligan APTS ke dalam 20 $\mathrm{mL}$ larutan natrium silikat. selanjutnya 
diasamkan dengan $\mathrm{HCl}$ hingga $\mathrm{pH}: 7$, dan yang lain hingga $\mathrm{pH}: 3$, sedangkan pembuatan silika gel tanpa penambahan APTS. Selanjutnya dilakukan aging, pencusian dan pengeringan, sehingga diperoleh hibrida amino-silika dan silika gel.

Menurut Schubert dan Husing (2000), pada kondisi basa, proses reaksi pembentukan gel atau lebih dikenal dengan proses sol-gel terjadi akibat penyerangan nukleofilik atom silikon oleh ion ${ }^{-} \mathrm{OH}$ atau $\mathrm{Si}^{-}{ }^{-}$, seperti ditampilkan pada gambar 1 . Ion ${ }^{-} \mathrm{OH}$ atau $\mathrm{Si}^{-} \mathrm{O}^{-}$terbentuk oleh disosiasi $\mathrm{H}^{+}$dari molekul air atau gugus $\mathrm{Si}$ OH. Pada reaksi hidrolisis, anion hidroksi menyerang atom silikon dengan mekanisme reaksi $\mathrm{SN}_{2}$ (substitusi nukleofilik) di mana $-\mathrm{OH}$ menggantikan -OR. Pada reaksi kondensasi, suatu nukleofilik ion silanolat menyerang spesies netral silikat dan akan menggantikan $\mathrm{OH}$ atau ${ }^{-} \mathrm{OR}$. Reaksi kondensasi relatif lebih cepat terhadap hidrolisis.

$$
\begin{aligned}
& \equiv \mathrm{Si}-\mathrm{OX}+\mathrm{YO}^{-} \rightleftharpoons\left[\left.\left.\right|_{\mathrm{MIN}} ^{\mathrm{OH}}\right|_{\mathrm{OX}} ^{\mathrm{OY}}\right]^{-} \rightleftharpoons \mathrm{Y}-\mathrm{O}-\mathrm{Si} \equiv+\mathrm{XO} \\
& \text { Ket: } \quad \mathrm{Y}=\mathrm{H}, \equiv \mathrm{Si} \\
& \text { Reaksi hidrolisis } \quad: \mathrm{X}=\mathrm{R}, \mathrm{Y}=\mathrm{H} \\
& \text { Reaksi kondensasi } \quad: \mathrm{X}=\mathrm{R} \text { atau } \mathrm{H}, \mathrm{Y}=\quad \mathrm{Si} \equiv
\end{aligned}
$$

Gambar 1. Mekanisme reaksi sol-gel pada keadaan basa (Scubert dan Husing, 2000)

Mekanisme reaksi dalam kondisi asam dapat dilihat pada gambar 2 .

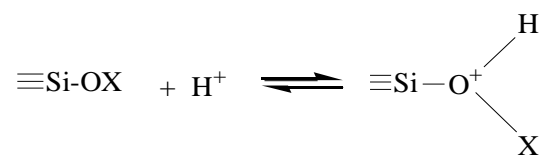

ket: $\mathrm{X}=\mathrm{R}, \mathrm{H}$

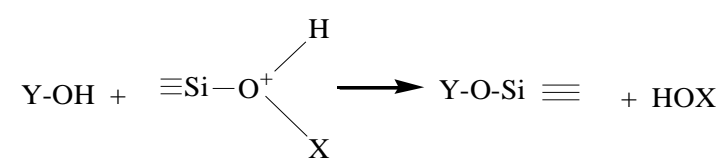

ket: $\mathrm{Y}=\mathrm{H}, \quad \mathrm{Si} \equiv$

reaksi hidrolisis : $\mathrm{X}=\mathrm{R}, \mathrm{Y}=\mathrm{H}$

reaksi kondensasi : $\mathrm{X}=\mathrm{R}$ atau $\mathrm{H}, \mathrm{Y}=\quad \mathrm{Si} \equiv$

Gambar 2. Mekanisme reaksi proses sol-gel pada kondisi asam
Pada kondisi asam, atom oksigen dari gugus Si$\mathrm{OH}$ atau Si-OR terprotonasi pada langkah pertama dengan cepat, seperti pada persamaan di atas. Gugus pergi yang baik terbentuk melalui protonasi tersebut. Kerapatan elektron dari atom pusat Si akan berkurang sehingga bersifat lebih elektrofilik dan lebih mudah untuk diserang oleh air (reaksi hidrolisis) atau gugus silanol (reaksi kondensasi). Pada kondisi ini, reaksi hidrolisis berlangsung lebih cepat dari pada reaksi kondensasi. Dengan melihat dua mekanisme yang berbeda dari kondisi asam dan basa ini, dapat dipahami mengapa jika gelasi dilakukan pada kondisi basa, akan berlangsung lebih cepat dibanding kondisi asam. Hal tersebut disebabkan pada kondisi basa, reaksi kondensasi berlangsung lebih cepat relatif terhadap reaksi hidrolisis, sedangkan pada kondisi asam terjadi sebaliknya, reaksi hidrolisis relatif lebih cepat dibanding reaksi kondensasi.

Mengacu pada gambar 1 dan gambar 2 di atas maka mekanisme reaksi pembentukan hibrida amino-silika kemungkinan mengikuti mekanisme reaksi $\mathrm{SN}_{2}$, diperkirakan seperti disajikan dalam gambar 3, dilanjutkan gambar 4 .

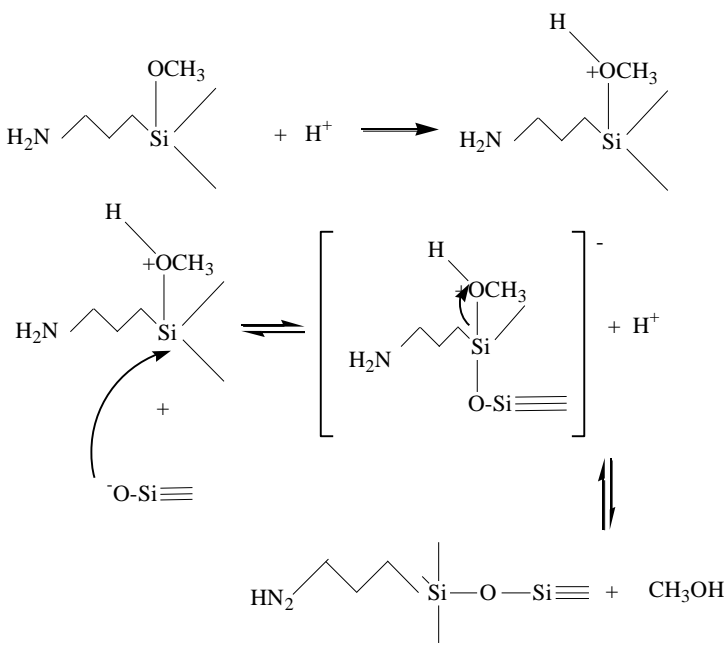

Gambar 3. Model mekanisme reaksi pembentukan dimer silosan pada pembuatan hibrida amino-silika

Kemungkinan pembentukan hibrida aminosilika diawali dengan protonasi atom $\mathrm{O}$ gugus metoksi $\left(-\mathrm{OCH}_{3}\right)$ pada senyawa organik 3aminopropiltrimetoksisilan (APTS) akibat penambahan asam. Selanjutnya spesies anion 
silikat yang berperan sebagai nukleofil akan menyerang atom Si pada APTS di mana atom O pada gugus metoksi telah terprotonasi. Spesies anion silikat yang masuk akan menggantikan gugus metoksi $-\mathrm{OCH}_{3}$ dengan atom $\mathrm{O}$ yang telah terprotonasi sehingga terbentuk ikatan siloksan. Gugus metoksi dengan atom $\mathrm{O}$ yang telah terprotonasi akan dilepaskan dalam bentuk metanol. Penambahan asam yang terus berlanjut mengakibatkan reaksi dapat terus berlanjut sampai semua gugus metoksi dalam senyaea organik APTS mengalami reaksi kondensasi denagn spesies anion silikat dengan melepas metanol.

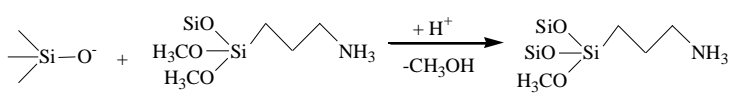

(A)

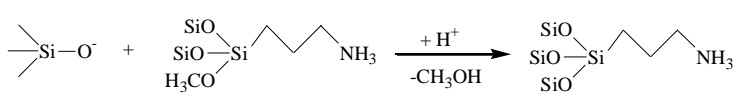

(B)

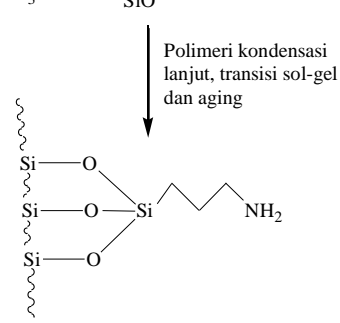

Gambar 4. Pembentukan hibrida amino-silika

Karakterisasi hasil dilakukan dengan spektrofotometer FTIR, ditampilkan dalam gambar 5. Untuk melihat keberhasilan sintesis bahan hibrida amino-silika ini, maka spektra FTIR dari amino-silika dibandingkan dengan silika tanpa ligan baik pada $\mathrm{pH}$ gelasi 7 maupun 3, dan spektra FTIR silika Kiesel gel 60 dari Merck sebagai standar. Serapan karakteristik untuk silika gel (Kiesel Gel 60) muncul pada bilangan gelombang $3448,5 \mathrm{~cm}^{-1}$ yang mengindikasikan adanya vibrasi $-\mathrm{OH}$ dari Si$\mathrm{OH}$, serapan lebar dan tajam pada $1101,3 \mathrm{~cm}^{-1}$ mengindikasikan vibrasi ulur asimetri Si-O dari Si-O-Si, $1637,5 \mathrm{~cm}^{-1}$ mengindikasikan adanya vibrasi tekuk -OH dari molekul air, $970,1 \mathrm{~cm}^{-1}$ mengindikasikan vibrasi ulur $\mathrm{Si}-\mathrm{O}$ dari $\mathrm{Si}-\mathrm{OH}$, dan serapan di 800,4 $\mathrm{cm}^{-1}$ mengindikasikan adanya vibrasi ulur simetri $\mathrm{Si}-\mathrm{O}$ dari $\mathrm{Si}-\mathrm{O}-\mathrm{Si}$ (Silverstein dkk., 1991)

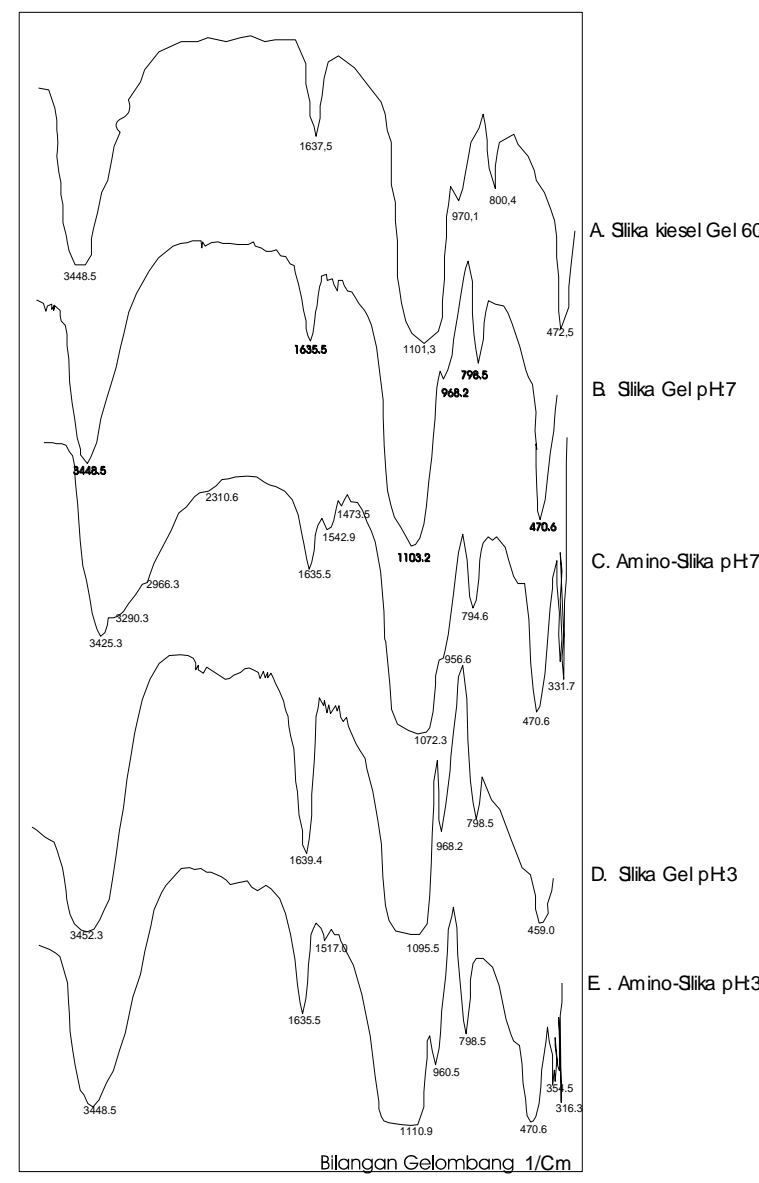

Gambar 5. Spektra FTIR dari silika gel dan hibrida amino-silika

Serapan di $472,5 \mathrm{~cm}^{-1}$ menunjukkan adanya vibrasi tekuk dari Si-O-Si (Hamdan, 1992). Silika gel hasil sintesis baik dengan $\mathrm{pH}$ gelasi 7 maupun 3 mempunyai serapan yang mirip dengan silika Kiesel Gel 60. Untuk hibrida amino-silika yang terbentuk pada $\mathrm{pH}$ gelasi 7 , muncul serapan-serapan baru yang tidak dimiliki oleh silika gel. Serapan baru tersebut di antaranya adalah serapan pada bilangan gelombang 3290,3 $\mathrm{cm}^{-1}$ yang menunjukkan vibrasi ulur simetris dari amina alifatik primer, serapan di 2966,3 $\mathrm{cm}^{-1}$ yang menunjukkan adanya vibrasi ulur dari rantai alifatik $-\mathrm{C}-\mathrm{H}$, didukung dengan vibrasi bengkok simetris dari - $\mathrm{CH}_{2}$ - yang muncul pada serapan $1473,5 \mathrm{~cm}^{-1}$. Muncul pula serapan pada $1542,9 \mathrm{~cm}^{-1}$, yang kemungkinan menunjukkan adanya vibrasi bengkok simetris dari -N-H (Silverstein dkk., 1991).

Untuk hibrida amino-silika yang terbentuk pada $\mathrm{pH}$ gelasi 3, hanya muncul satu serapan baru, yaitu di 1517,0 cm-1 dengan intensitas rendah, 
sehingga tidak cukup kuat untuk menunjukkan kemungkinan terbentuknya bahan hibrida amino-silika. Kalau dianggap sintesis ini berhasil, kemungkinan gugus $-\mathrm{NH}_{2}$ yang berhasil terimobilisasi sangat kecil. Hal ini kemungkinan bisa terjadi karena pada penambahn asam yang terus menerus sampai $\mathrm{pH}=3$ kemungkinan $\mathrm{H}^{+}$yang ditambahkan tidak hanya memprotonasi gugus metoksi dari APTS tetapi justru memutuskan gugus $-\mathrm{NH}_{2}$ untuk membentuk spesies yang lain.

Pada $\mathrm{pH}$ gelasi yang berbeda, kondisi yang paling mencolok adalah serapan di $1635,5 \mathrm{~cm}^{-1}$. Pada silika gel $\mathrm{pH}$ gelasi 3, pita ini intensitasnya jauh lebih besar dibanding pada $\mathrm{pH}$ gelasi 7 , hal ini kemungkinan menunjukkan bahwa pada kondisi ini silika gel mengikat molekul air relatif lebih banyak; dan hal ini didukung menguatnya intensitas serapan pada 968,2 $\mathrm{cm}^{-1}$. Jika banyaknya molekul air yang terikat setara dengan porositas padatan, maka dapat dilihat bahwa masuknya gugus organik mengurangi intensitas dari kedua serapan ini. Dengan kata lain imobilisasi gugus amino dalam silika terutama pada $\mathrm{pH}$ gelasi 7 dapat dinyatakan telah berhasil dilakukan.

Dilakukan pula karakterisasi menggunakan defraktometer sinar-X, yang akan memberikan informasi mengenai struktur kristal dari hibrida amino-silika. Defraktogram dari hibrida aminosilika diberikan pada gambar 6.

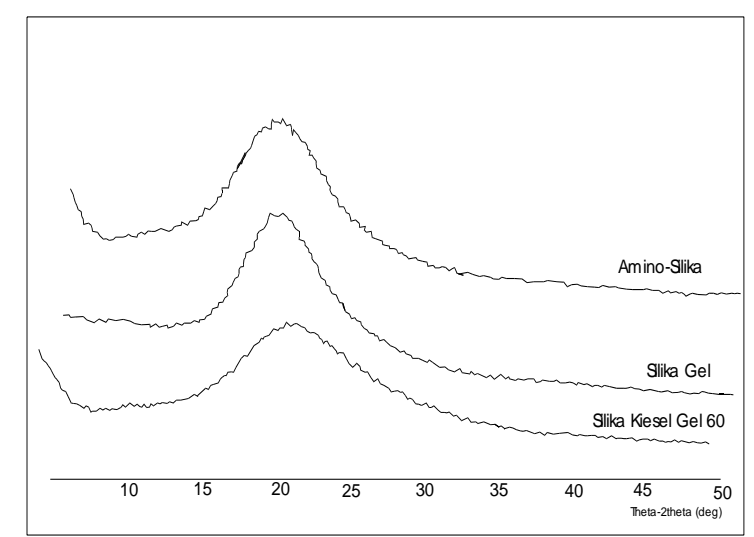

Gambar 6. Difraktogram silika gel dan hibrida amino-silika pada $\mathrm{pH}$ gelasi 7 .

Dari gambar 4. dapat dilihat bahwa seperti halnya silika gel, hibrida amino-silika yang terbentuk pada $\mathrm{pH}$ gelasi 7 bersifat amorf, karena menunjukkan satu puncak melebar dengan $2 \theta=21-22^{\circ}$ (Kalapathy dkk., 2000).

Karakterisasi dilakukan pula dengan uji adsorpsi terhadap logam Ni (II). Menurut aturan Hard and Soft Acids-Bases (HSAB) Pearson, Ni (II) merupakan logam golongan asam menengah (borderline), sedangkan gugus $-\mathrm{OH}$ dan $-\mathrm{NH}_{2}$ merupakan basa keras, di mana-OH lebih keras dibandingkan $-\mathrm{NH}_{2}$ (Shriver dkk., 1990). Interaksi Ni (II) dengan silika gel dan aminosilika bisa dilihat untuk menguji hal tersebut.

Persamaan Isoterm adsorpsi Langmuir (Oscik, 1982) digunakan untuk mengestimasi kapasitas adsorpsi dari masing-masing padatan sebagai adsorben. Harga parameter adsorpsi ditampilkan dalam tabel 1 .

Tabel 1 menunjukkan bahwa amino-silika dengan $\mathrm{pH}$ gelasi 7 memberikan kapasitas adsorpsi jauh lebih tinggi dibanding adsorben lainnya. Hal ini kemungkinan mendukung asumsi sebelumnya menurut aturan Pearson, bahwa interaksi Ni (II) dengan padatan adalah interaksi kimia, yaitu interaksi asam-basa. Di samping itu juga mendukung karakterisasi sebelumnya, bahwa $\mathrm{pH}$ gelasi 7 lebih mendukung keberhasilan imobilisasi amino dalam silika melalui proses sol-gel.

Tabel 1. Kapasitas adsorpsi dan energi adsorpsi $\mathrm{Ni}$ (II) pada adsorben silika gel dan hibrida silika-amino

\begin{tabular}{|c|c|c|c|}
\hline \multirow[b]{2}{*}{$\begin{array}{c}\text { Adsorbe } \\
\mathrm{n}\end{array}$} & \multicolumn{3}{|c|}{ Kapasitas dan energi adsorpsi Ni (II) } \\
\hline & $\begin{array}{l}\text { Kapasita } \\
\text { s } \\
\text { Adsorpsi } \\
\text { (b) } 10^{-3} \\
\text { x mol/g }\end{array}$ & $\begin{array}{c}\text { Tetapan } \\
\text { Kesetimbang } \\
\text { an adsorpsi, } \\
\mathrm{K}(\mathrm{L} / \mathrm{mol})\end{array}$ & $\begin{array}{c}\text { Energi } \\
\text { Adsorpsi } \\
(\mathrm{kJ} / \mathrm{mol})\end{array}$ \\
\hline SG (I) & 0,215 & $1.163,415$ & 17,498 \\
\hline SG (II) & 8,795 & $9.475,000$ & 22,697 \\
\hline $\begin{array}{l}\text { Am-SG } \\
\text { (I) }\end{array}$ & 1,230 & 579,372 & 15,770 \\
\hline $\begin{array}{c}\text { Am-SG } \\
\text { (II) }\end{array}$ & 105,600 & 607,212 & 15,886 \\
\hline
\end{tabular}

Keterangan: 
SG (I): silika gel dengan pH gelasi 3

$\mathrm{SG}$ (II): silika gel dengan $\mathrm{pH}$ gelasi 7

Am-SG (I): Amino-silika dengan pH gelasi 3

Am-SG (II): Amino-silika dengan pH gelasi 7.

\section{KESIMPULAN}

Dari hasil penelitian dan pembahasan dapat diambil beberapa kesimpulan sebagai berikut:

1. Abu sekam padi dapat dijadikan sebagai sumber silika pada pembuatan silika gel dan bahan hibrida amino-silika.

2. Pembuatan bahan hibrida amino-silika dapat dilakukan dengan mengimobilkan 3aminopropiltrimetoksisilan dalam silika dari abu sekam padi melalui proses sol-gel dengan pH gelasi 7.

\section{UCAPAN TERIMAKASIH}

Penulis mengucapkan terimakasih kepada Dirjen Dikti melalui Program Hibah Pekerti Angkatan II/2 tahun 2005 yang telah membantu dalam pendanaan penelitian dan kepada saudari Agnes Retno Iswari yang telah membantu dalam pengumpulan data.

\section{DAFTAR PUSTAKA}

Brinker, C.J., dan W.J. Scherer, 1990, Sol-Gel Science: The Physics and Chemistry of SolGel Processing, Academic Press, san Diego.

Priyosulistyo, HRC., Sudarmoko, Bambang Supriyadi, Bambang Suhendro, dan P. Sumardi, 1999, Pemanfaatan Limbah Abu Sekam Padi Untuk Peningkatan Mutu Beton, Laporan Penelitian Hibah Bersaing VI/2, Lembaga Penelitian UGM

Sriyanti, Narsito, Nuryono, 2001, Selektivitas 2Merkaptobenzotiazol Terimpregnasi pada Zeolit Alam untuk Adsorpsi Kadmium (II) dalam Campuran Kadmium (II)-Besi (III), Proseding Seminar Nasional Kimia IX, Yogyakarta

Oscik, J., 1982, Adsorption, Ellis Horwood Limited, Chichester.

Bhatia, R.B., and C.J. Brinker, 2000, Chem.Mater., 12, 2434 - 2441.

Scott, R.P.W., 1993, Silika Gel and Bonded Phases: Their Production, Properties and Use in LC, John Wiley \& Sons, Toronto.
Sriyanti, Taslimah, Nuryono dan Narsito, 2004, Selektivitas Silika Gel Termodifikasi Gugus Tiol Untuk Adsorpsi Kadmium (II) dan Tembaga (II), Proceeding Seminar Nasional Hasil Penelitian MIPA 2004, FMIPA Undip, Semarang.

Kalapathy, U., A. Proctor and J. Shultz, 2000, A Simple Method For Production of Pure Silica From Rice Hull Ash, Bioresource Technology 73, 257-262.

Nuryono, 2004, Effect of NaOH Concentration On Destruction of rice Husk Ash With Wet Technique, Proceeding Seminar Nasional Hasil Penelitian MIPA 2004, FMIPA Undip, Semarang

Iler, R.K., 1979, Silica Gels and Powder, dalam Iler, R.K. (Ed), The Chemistry of Silica, Wiley, New York.

Schubert, U., dan N. Husing, 2000, Synthesis of Inorganic Material, Willey-VCH Verlaq Gmbh, D-69469 Wernbeim, Federal Replublic of Germany.

Silverstein, R. M., G. C. Bassler and T. C. Morril, 1991, Spectrometric Identification of Organic Compound, 5th ed, John Wiley $\&$ Sons, Inc., New York.

Hamdan, H., 1992, Introduction to Zeolites: Synthesis, Characterization and Modification, Universiti Teknologi Malaysia, Kualalumpur.

Shriver, D.F., Atkins, P.W. dan Langford, C.H., 1990, Inorganic Chemistry, Oxford University Press, Oxford 